\title{
Landiolol in patients with septic shock resident in an intensive care unit (LANDI- SEP): study protocol for a randomized controlled trial
}

Martin Unger ${ }^{1 *}$ (D), Andrea Morelli ${ }^{2}$, Mervyn Singer ${ }^{3}$, Peter Radermacher ${ }^{4}$, Sebastian Rehberg ${ }^{5}$, Helmut Trimmel $^{6}$, Michael Joannidis ${ }^{7}$, Gottfried Heinz ${ }^{8}$, Vladimír Cerny ${ }^{9}$, Pavel Dostál ${ }^{10}$, Christian Siebers ${ }^{11}$, Fabio Guarracino ${ }^{12}$, Francesca Pratesi ${ }^{13}$, Gianni Biancofiore ${ }^{14}$, Massimo Girardis ${ }^{15}$, Pavla Kadlecova ${ }^{16}$, Olivier Bouvet ${ }^{17}$, Michael Zörer ${ }^{1}$, Barbara Grohmann-Izay' ${ }^{1}$ Kurt Krejcy ${ }^{1}$, Christoph Klade ${ }^{1}$ and Günther Krumpl'

\begin{abstract}
Background: In patients with septic shock, the presence of an elevated heart rate (HR) after fluid resuscitation marks a subgroup of patients with a particularly poor prognosis. Several studies have shown that HR control in this population is safe and can potentially improve outcomes. However, all were conducted in a single-center setting. The aim of this multicenter study is to demonstrate that administration of the highly beta1-selective and ultrashortacting beta blocker landiolol in patients with septic shock and persistent tachycardia (HR $\geq 95$ beats per minute [bpm]) is effective in reducing and maintaining HR without increasing vasopressor requirements.
\end{abstract}

Methods: A phase IV, multicenter, prospective, randomized, open-label, controlled study is being conducted. The study will enroll a total of 200 patients with septic shock as defined by The Third International Consensus Definitions for Sepsis and Septic Shock criteria and tachycardia (HR $\geq 95 \mathrm{bpm})$ despite a hemodynamic optimization period of 24-36 h. Patients are randomized (1:1) to receive either standard treatment (according to the Surviving Sepsis Campaign Guidelines 2016) and continuous landiolol infusion to reach a target HR of 80-94 bpm or standard treatment alone. The primary endpoint is HR response (HR 80-94 bpm), the maintenance thereof, and the absence of increased vasopressor requirements during the first $24 \mathrm{~h}$ after initiating treatment.

Discussion: Despite recent studies, the role of beta blockers in the treatment of patients with septic shock remains unclear. This study will investigate whether HR control using landiolol is safe, feasible, and effective, and further enhance the understanding of beta blockade in patients with septic shock.

Trial registration: EU Clinical Trials Register; EudraCT, 2017-002138-22. Registered on 8 August 2017.

Keywords: Septic shock, Sepsis, Beta-blocker, Landiolol, Tachycardia, Randomized controlled trial

\footnotetext{
* Correspondence: martin.unger@aoporphan.com

${ }^{1}$ AOP Orphan Pharmaceuticals AG, Wilhelminenstraße 91/ll f, 1160 Vienna,

Austria

Full list of author information is available at the end of the article
}

(c) The Author(s). 2018 Open Access This article is distributed under the terms of the Creative Commons Attribution 4.0 International License (http://creativecommons.org/licenses/by/4.0/), which permits unrestricted use, distribution, and reproduction in any medium, provided you give appropriate credit to the original author(s) and the source, provide a link to the Creative Commons license, and indicate if changes were made. The Creative Commons Public Domain Dedication waiver (http://creativecommons.org/publicdomain/zero/1.0/) applies to the data made available in this article, unless otherwise stated. 


\section{Background}

In the early phase of septic shock, overwhelming inflammation leads to vasodilation and capillary leakage, which decreases cardiac output due to both absolute and relative hypovolemia [1-3]. These alterations trigger massive sympathetic activation in the attempt to maintain vital organ perfusion. Tachycardia and vasoconstriction are the hallmarks of this activation and compensate for systemic vasodilatation [4]. In the very early phase of the septic insult, tachycardia is the main compensatory mechanism to maintain cardiac output despite the reduction of preload. Accordingly, current sepsis guidelines recommend intravascular fluid administration as the first step to counteract hypotension [4]. Compensatory tachycardia implies preserved baroreceptor and chemoreceptor activity, thus the majority of patients with sepsis rapidly respond to volume administration with a reduction of tachycardia.

However, some patients with sepsis continue to have an elevated heart rate (HR) despite adequate fluid resuscitation. This elevated HR reflects sympathetic overstimulation resulting from dysregulation of the autonomic nervous system [5-12] in addition to the effect of exogenous catecholamines [7].

Elevated HR has been associated with a poor outcome, but it is unclear whether it is a surrogate of disease severity or whether it plays a pathophysiological role that could be treated to improve patient outcomes [13-16].

Beta-blockers are potential candidates to control HR and numerous animal models provide a rationale for their use during sepsis [17-24]. Despite concerns of hemodynamic decompensation, recent clinical studies using esmolol in patients with sepsis [10, 25-34] suggest that control of $\mathrm{HR}$ can be safely achieved with beta1-selective beta-blockers. These studies reported a decrease in HR with limited reduction of cardiac output, improved stroke volume and lactate levels, and stabilization or improvement of organ dysfunction [10, 28-30, 32]. Furthermore, the combined use of beta-blockers and vasopressors appears to be safe and does not appear to increase the need for vasopressor support or impair microcirculation [26, 27, 34]. However, all of the previously reported studies were conducted in single centers with relatively small sample sizes and only one study included a Caucasian population.

Landiolol, the beta-blocker used in our study, is a highly beta1-selective, ultrashort-acting beta-blocker that could be ideally suited for the treatment of critically ill patients due to its limited hypotensive effect [35-38].

The aim of this multicenter, prospective, controlled study is to demonstrate that the administration of the ultrashort-acting beta-blocker landiolol in patients with septic shock and persistent tachycardia (HR $\geq 95$ beats per minutes $[\mathrm{bpm}]$ ) is effective in reducing and maintaining HR without increasing vasopressor requirements.

\section{Methods/Design}

\section{Study design and objective}

This is a phase IV, multicenter, prospective, randomized, open-label, controlled study on landiolol in a septic shock population (as defined by The Third International Consensus Definitions for Sepsis and Septic Shock criteria [39]) hospitalized in an intensive care unit (ICU). The study duration is expected to be 24 months from first patient enrolled until completion of the final visit for the last patient. Participating centers are listed in Table 1.

The study objective is to compare the percentage of patients with a HR response (defined as HR within the target range of $80-94 \mathrm{bpm}$ ) and maintenance thereof without an increase in vasopressor requirements within the first $24 \mathrm{~h}$ of treatment, and to further assess efficacy and safety in the two treatment arms: standard of care treatment and landiolol (landiolol group) or standard of care treatment alone (control group).

Additional file 1 contains the completed Standard Protocol Items: Recommendations for Interventional Trials (SPIRIT) checklist.

\section{Study population}

This study will enroll a total of 200 patients with septic shock and elevated HR ( $\geq 95 \mathrm{bpm})$ despite a hemodynamic optimization phase of at least $24 \mathrm{~h}$ but a maximum of $36 \mathrm{~h}$ in which they received adequate fluid resuscitation and continuous vasopressor treatment (according to the Surviving Sepsis Campaign Guidelines 2016 [40]). Detailed inclusion and exclusion criteria are displayed in Table 2.

\section{Randomization, blinding, and treatment allocation}

Patients fulfilling the selection criteria are randomized in a 1:1 ratio to one of the two groups (landiolol or control) after informed consent, as required by local law, has been obtained. The presence of atrial fibrillation in the hemodynamic optimization period is used as a stratification factor for randomization. As this is an open label study, investigators and other study personnel will not be blinded to the treatment.

\section{Study drug}

Lyophilized landiolol hydrochloride $300 \mathrm{mg}$ (Rapibloc Lyo, $300 \mathrm{mg}$ ) is to be reconstituted in $50 \mathrm{~mL}$ of $0.9 \%$ $\mathrm{NaCl}$ to a concentration of $6 \mathrm{mg} / \mathrm{mL}$ before use.

\section{Treatments}

\section{Landiolol group}

Patients in the landiolol group begin continuous infusion with landiolol within $2 \mathrm{~h}$ after randomization at a starting dose of $1 \mathrm{mcg} / \mathrm{kg} / \mathrm{min}$. The dose is to be progressively increased at increments of $1 \mathrm{mcg} / \mathrm{kg} / \mathrm{min}$ to a 
Table 1 List of participating centers and ethics committee approvals

\begin{tabular}{|c|c|c|c|c|}
\hline Participating center & $\mathrm{Pl}$ & Central Ethics committee & Reference number & Approval date \\
\hline $\begin{array}{l}\text { Medical University Vienna, Department } \\
\text { of Internal Medicine II. Division of } \\
\text { Cardiology }\end{array}$ & Gottfried Heinz, MD & $\begin{array}{l}\text { Ethics Committee, Medical } \\
\text { University Vienna }\end{array}$ & ECS 1805/2017 & 15 September 2017 \\
\hline $\begin{array}{l}\text { Medical University Innsbruck, Division of } \\
\text { Emergency Medicine and Intensive } \\
\text { Care, Department Internal Medicine }\end{array}$ & Michael Joannidis, MD & & & \\
\hline $\begin{array}{l}\text { State Hospital Wiener Neustadt, } \\
\text { Department of Anesthesiology, } \\
\text { Emergency Medicine and General } \\
\text { Intensive Care }\end{array}$ & Helmut Trimmel, MD, MSc & & & \\
\hline $\begin{array}{l}\text { University Hospital Greifswald, } \\
\text { Department of Anesthesiology, } \\
\text { Intensive Care, Emergency and Pain } \\
\text { Medicine }\end{array}$ & Sebastian Rehberg, MD & $\begin{array}{l}\text { Ethics Committee, } \\
\text { University Hospital } \\
\text { Greifswald }\end{array}$ & FFV 06/17 & 15 February 2018 \\
\hline $\begin{array}{l}\text { University Hospital Munich, Department } \\
\text { of Anesthesiology }\end{array}$ & Christian Siebers, MD & & & \\
\hline $\begin{array}{l}\text { University Hospital Hradec Králové, } \\
\text { Department of Anesthesiology, } \\
\text { Resuscitation and Intensive Medicine }\end{array}$ & Pavel Dostál, MD, PhD, MBA & $\begin{array}{l}\text { Ethics Committee, } \\
\text { University Hospital Hradec } \\
\text { Králové }\end{array}$ & $2018011126 \mathrm{M}$ & 07 November 2017 \\
\hline $\begin{array}{l}\text { Masaryk Hospital, Department of } \\
\text { Anesthesiology, Perioperative Medicine } \\
\text { and Intensive Care }\end{array}$ & Vladimír Černý, MD, PhD, FCCM & & & \\
\hline $\begin{array}{l}\text { University Hospital La Sapienza, } \\
\text { Department of Anesthesiology and } \\
\text { Intensive Care }\end{array}$ & Andrea Morelli, MD. & $\begin{array}{l}\text { Ethics Committee, } \\
\text { University Hospital La } \\
\text { Sapienza }\end{array}$ & 4846 & 08 February 2018 \\
\hline $\begin{array}{l}\text { Azienda Ospedaliero Universitaria } \\
\text { Pisana, Department of Anesthesiology } \\
\text { and Resuscitation } 5\end{array}$ & Fabio Guarracino, MD & & & \\
\hline $\begin{array}{l}\text { Azienda Ospedaliero Universitaria } \\
\text { Pisana, Department of Anesthesiology } \\
\text { and Resuscitation } 6\end{array}$ & Francesca Pratesi, MD & & & \\
\hline $\begin{array}{l}\text { University School of Medicine Pisa, } \\
\text { Department of Anesthesiology and } \\
\text { Transplant Intensive Care Unit }\end{array}$ & Gianni Biancofiore, MD & & & \\
\hline $\begin{array}{l}\text { University Hospital Modena, } \\
\text { Department of Anesthesia and Intensive } \\
\text { Care }\end{array}$ & Massimo Girardis, MD & & Approval pending & \\
\hline
\end{tabular}

maximum of $40 \mathrm{mcg} / \mathrm{kg} / \mathrm{min}$ at intervals of at least 20 min to obtain and maintain a HR of $80-94 \mathrm{bpm}$. Landiolol must be infused continuously to maintain the target HR until one the following events occurs: discontinuation of vasopressor infusion; death; a serious adverse event $(\mathrm{AE})$ attributable to the study drug that necessitates study drug discontinuation as determined by the investigator; patient discharge from the ICU; or day 28 of study participation.

\section{Control group}

Patients in the control group receive standard of care treatment according to the Surviving Sepsis Campaign Guidelines 2016 [40], which does not specify a target for HR control. Patients in the control group are to be withdrawn from the study if they receive beta-blocker treatment.

\section{Patient assessments}

Heart rate, blood pressure, and body temperature will be documented hourly for the first $24 \mathrm{~h}$ after treatment start and every $12 \mathrm{~h}$ thereafter in both treatment groups, and additionally at every dose change of landiolol in the landiolol group. Clinical laboratory analysis including blood gas analysis will be performed daily for the first four days of the study. Sequential Organ Failure Assessment (SOFA) score will be assessed daily for the first four days and every third day thereafter. If performed, hemodynamic parameters (CO, CI, GEDI, ELWI, PAOP, MPAP, LVEF, TAPSE, VTI) obtained by PICCO/FloTrac, Swan-Ganz catheter or Cardiac Echo will be documented. Concomitant medication and AE will be documented over the entire study period. Measurements and assessments performed in both groups are listed in Fig. 1 in the completed SPIRIT figure. 
Table 2 Inclusion/exclusion criteria

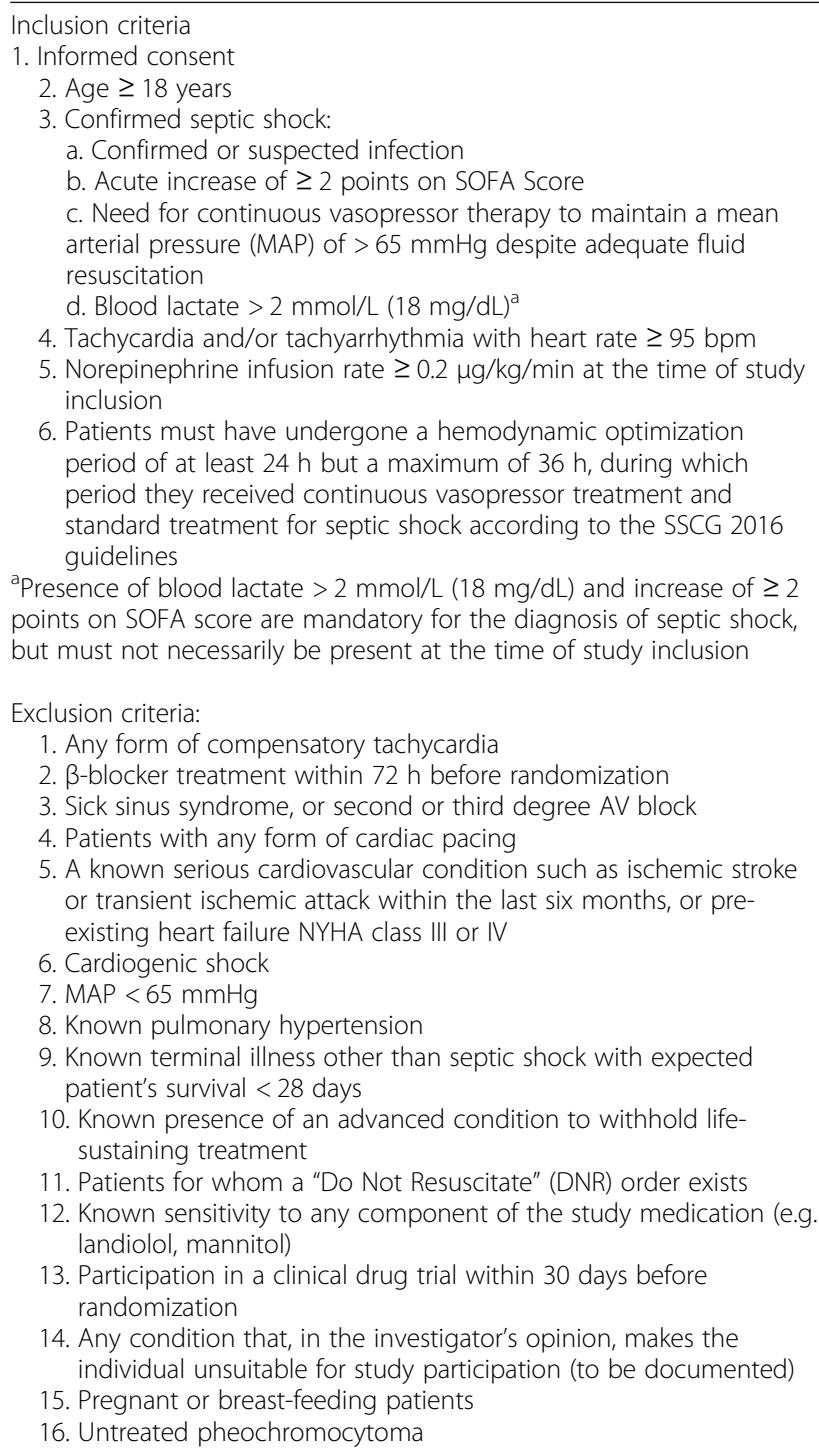

NYHA New York Heart Association

\section{Endpoints}

The primary efficacy endpoint is $\mathrm{HR}$ response $(\mathrm{HR}=$ 80-94 bpm) and maintenance thereof without increase in vasopressor requirements during the first $24 \mathrm{~h}$ after treatment start.

Secondary efficacy endpoints will consist of ICU and 28-day mortality, ICU and hospital stay duration, SOFA score, and inotrope and vasopressor support requirements. Efficacy and safety endpoints are listed in Table 3.

\section{Data collection}

Data will be collected and entered into the electronic data capture system by trained study personnel (investigators and study nurses).

\section{Sample size}

Sample size estimation is based upon the assumption that $60 \%$ of patients in the landiolol group reach the primary endpoint versus $40 \%$ of patients in the control group. The sample size of 200 patients will provide $80 \%$ power to demonstrate a statistically significant difference (upon standard level alpha $=0.05$ ) between the treatment groups using a Chi-square test. The sample size in the study by Morelli et al. [10] was adequate considering that to detect a $20 \%$ change in HR with a power of $80 \%$ at a level of significance of alpha $=0.05,64$ patients per group would have been required. In order to detect the binary primary endpoint of our study an additional 36 patients per group are required.

\section{Statistical analysis}

The hypothesis that Group L is superior to Group C in proportion of patients who reached the primary endpoint will be demonstrated if the lower limit of the two-sided 95\% Newcombe confidence interval of difference $\mathrm{pL}-\mathrm{pC}$ is above zero, where $\mathrm{pL}$ and $\mathrm{pC}$ are percentages of patients who reached the primary endpoint in Group L and Group C, respectively. P values based on Cochran-Mantel-Haenszel (according to $\mathrm{SAS}^{\bullet}$ terminology) will be presented together with the confidence intervals to evaluate statistical significance of association between treatment group and outcome after adjustment for the stratification group. For the purpose of exploratory analysis, the individual criteria of the primary endpoint, heart rate response (i.e. $\mathrm{HR}=80-94 \mathrm{bpm}$ ) reached (also defined as secondary endpoint), heart rate response reached and maintained and no increase in vasopressor requirements during the first $24 \mathrm{~h}$, will be compared separately between treatment groups. Additional subgroup and sensitivity analyses will have exploratory character and will be defined in all details in the SAP.

Secondary endpoints with continuous, ordinal, and binary variables measured at multiple time-points will be analyzed as longitudinal data by linear, ordinal logistic, logistic, or log-binomial regression models with repeated measures. Covariates used in the models will be (but not limited to) treatment, visit, stratification group, and interaction treatment/visit. For continuous variables baseline value of the outcome variable will be a covariate as well. Distribution of data and a feasibility check of planned analyses will be performed before finalization of SAP and alternative statistical methods will be defined if assumptions on the application of the planned methods are not met (e.g. In-transformation of data, non-parametric method, or other alternative way). ICU mortality and 28-day mortality will be analyzed using the same methods as for the primary endpoint. Duration of ICU stay and duration of hospital stay (in survivors/ 


\begin{tabular}{|c|c|c|c|c|c|c|c|}
\hline \multirow[b]{3}{*}{ TIMEPOINT** } & \multicolumn{7}{|c|}{ STUDY PERIOD } \\
\hline & \multirow[t]{2}{*}{ Enrolment } & \multirow{2}{*}{$\begin{array}{c}\text { Allocation } \\
0\end{array}$} & \multicolumn{4}{|c|}{ Post-allocation } & \multirow{2}{*}{$\frac{\text { Close-out }}{\text { Day } 28}$} \\
\hline & & & $T 1$ & $T 2$ & $T 3$ & $T 4$ & \\
\hline \multicolumn{8}{|l|}{ ENROLMENT: } \\
\hline Eligibility screen & $\mathrm{x}$ & & & & & & \\
\hline \multirow{2}{*}{$\begin{array}{l}\text { Informed consent } \\
\text { Randomization }\end{array}$} & $x$ & & & & & & \\
\hline & & $x$ & & & & & \\
\hline \multicolumn{8}{|l|}{ INTERVENTIONS: } \\
\hline \multicolumn{8}{|l|}{$\begin{array}{l}\text { Landiolol infusion } \\
\text { (Landiolol Group) }\end{array}$} \\
\hline \multicolumn{8}{|l|}{$\begin{array}{l}\text { Standard treatment } \\
\text { (Control Group) }\end{array}$} \\
\hline \multicolumn{8}{|l|}{ ASSESSMENTS: } \\
\hline $\begin{array}{l}\text { Medical history, } \\
\text { Demographics, APACHE II }\end{array}$ & & & $\mathrm{x}$ & & & & \\
\hline Heart rate, MAP & & & $x^{2}$ & $X^{b}$ & $x^{b}$ & $X^{b}$ & \\
\hline $\begin{array}{l}\text { Haemodynamic } \\
\text { assessments: } \\
\text { Cardiac Echo, } \\
\text { PICCO/FloTrac", } \\
\text { Swan Ganz Catheter* }\end{array}$ & & & $x$ & $\mathrm{X}^{*}$ & $x^{*}$ & $\mathrm{x}^{*}$ & \\
\hline $\begin{array}{l}\text { Vasopressor/inotrope } \\
\text { requirements }\end{array}$ & & & $x$ & $x$ & $x$ & $\mathrm{x}$ & \\
\hline SOFA Score & & & $\mathrm{x}$ & $x$ & $x$ & $X^{* *}$ & \\
\hline Clinical labs & & & $x$ & $x$ & $x$ & & \\
\hline Adverse Events & & & $x$ & $x$ & $x$ & $x$ & $x$ \\
\hline
\end{tabular}

Fig. 1 Schedule of enrolment and assessments (SPIRIT 2013 Figure)

non-survivors) will be analyzed as time-to-event data (using Kaplan-Meier curve and using log-rank test or Wilcoxon test and/or proportional hazards regression model if appropriate).

For secondary analyses, no multiplicity adjustment is planned; therefore, a higher rate of type-I error must be considered in interpretation of results of secondary analyses. The analysis of secondary endpoints/analyses can provide supportive evidence related to the primary objective, but no confirmatory conclusion based on secondary analyses can be done.

\section{Discussion}

Despite intensive research, morbidity and mortality of patients with sepsis remain high [39]. Hence, novel therapeutic concepts are urgently needed. Recently, the use of beta-blockers during sepsis has been suggested $[10,28-30,32,41]$. This represents a true innovation, as current guidelines recommend beta-mimetics [40]. The potential benefits of beta-blockers are most likely due to their pleotropic effects and include myocardial protection, modulation of inflammatory processes, and improvements in organ functions [3, 22, 42-44]. However, it is still unclear which patients would benefit most from this intervention.

Morelli et al. [10] (and later others [28-30, 32]) showed that a HR reduction in patients with septic shock, after adequate resuscitation with fluids, vasopressors, and inotropes, was not associated with an increase in AEs and did not trigger an increase in vasopressor support. As in the original protocol by Morelli et al. [10], the target HR in the present study is $<95 \mathrm{bpm}$, which is based on studies showing poorer patient outcomes when this threshold is exceeded and studies showing good tolerance after achieving this target with beta-blockers [7, 11, 45-48]. More recently, several studies conducted in China [28-30,32] that selected a similar HR target showed good tolerance of the beta-blocker 
Table 3 Efficacy and safety endpoints

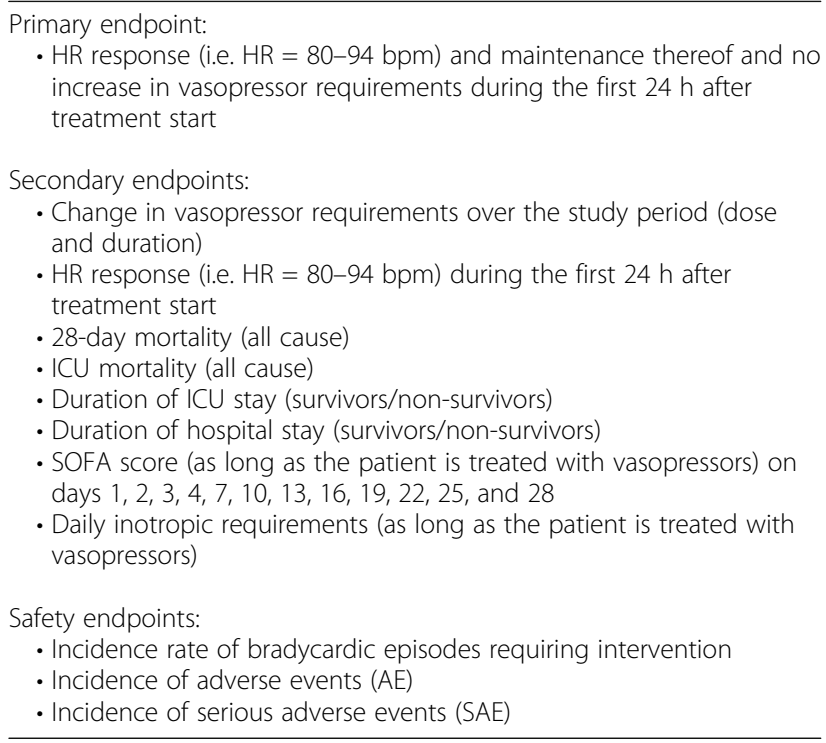

treatment. Therefore, the HR target of $<95 \mathrm{bpm}$ seems appropriate for further comparison and optimal with respect to feasibility and tolerance.

In order to minimize the risk of hemodynamic compromise, patients are only included in the study after at least $24 \mathrm{~h}$ of adequate fluid resuscitation and vasopressor support. In addition, landiolol is started at a low dose of 1 $\mathrm{mcg} / \mathrm{kg} / \mathrm{min}$ (as supported by landiolol sepsis [49], postoperative [50], and heart failure studies [51]) and titration is performed conservatively at $20-\mathrm{min}$ intervals (5 half-lives) [35]. The HR target should be reached within the first $24 \mathrm{~h}$, as supported by published data [28-30, 32].

Esmolol is the beta-blocker that has been most frequently evaluated in patients with sepsis, as its pharmacokinetic profile allows for rapid titration when used intravenously [10, 27-29, 31]. However, landiolol has demonstrated a more favorable pharmacokinetic and pharmacodynamic profile than esmolol [52-55]. Landiolol has a faster onset ( $1 \mathrm{~min}$ vs $2 \mathrm{~min}$ ) and shorter half-life (4 min vs $9 \mathrm{~min}$ ) than esmolol, which should allow for more rapid titration and enhanced safety [35]. Furthermore, the beta1 selectivity of landiolol is eight times higher than that of esmolol, resulting in a beta1/beta2 ratio of 255 [35]. This provides landiolol with more profound negative chronotropic effects and a lesser degree of negative inotropic and hypotensive action [36-38, 56].

This study will investigate whether HR control using the short-acting beta-blocker landiolol is feasible, safe, and effective in patients with septic shock and persistent tachycardia, and provide a better understanding of the potential role of beta-blockers in this patient population.

\section{Trial status}

Protocol version 3.0 dated 3 January 2018. The first participant was enrolled on 24 February 2018.

\section{Additional file}

Additional file 1: Checklist_SPIRIT_guidelines.pdf, Checklist of the Standard Protocol Items: Recommendations for Interventional Trials (SPIRIT) guidelines. (PDF $129 \mathrm{~kb}$ )

\section{Abbreviations \\ APACHE II: Acute Physiology and Chronic Health Evaluation II; AV: Atrioventricular; Bpm: Beats per minute; Cl: Cardiac Index; CO: Cardiac output; ELWI: Extravascular lung water index; GEDI: Global end-diastolic vol- ume index; HR: Heart rate; ICU: Intensive care unit; LVEF: Left ventricular ejection fraction; MPAP: Mean pulmonary arterial pressure; PAOP: Pulmonary arterial occlusion pressure; NYHA: New York Heart Association; PICCO: Pulse contour cardiac output; SOFA: Sequential Organ Failure Assessment; \\ SPIRIT: Standard Protocol Items: Recommendations for Interventional Trials; \\ TAPSE: Tricuspid annular plane systolic excursion; VTI: Velocity time integral}

\section{Acknowledgements}

We would like to thank Dr. Alain Rudiger for his support and feedback during the writing of the study protocol and this publication.

\section{Funding}

This study is sponsored by AOP Pharmaceuticals AG and co-sponsored by Amomed Pharma GmbH.

Availability of data and materials

Not applicable.

\section{Authors' contributions}

MU, AM, MS, PR, SR, HT, MJ, KK, GH, VC, PD, CS, FG, FP, GB, MG, BGI, MZ, CKL, and GK contributed to the design of the trial. PK provided the statistical analysis. MU and $\mathrm{OB}$ drafted the manuscript. All authors read and approved the final manuscript.

Ethics approval and consent to participate

Approvals of central ethics committees are listed in Table 1.

Consent for publication

Not applicable.

\section{Competing interests}

MU, GK, BGI, MZ, KK, and CK are employees of AOP Pharmaceuticals AG, OB is an employee of Amomed Pharma GmbH.

\section{Publisher's Note}

Springer Nature remains neutral with regard to jurisdictional claims in published maps and institutional affiliations.

\section{Author details}

1AOP Orphan Pharmaceuticals AG, Wilhelminenstraße 91/II f, 1160 Vienna, Austria. ${ }^{2}$ Department of Anesthesiology and Intensive Care, University Hospital La Sapienza, Policlinico Umberto I, Rome, Italy. Intensive Care Medicine, University College London, London, UK. ${ }^{4}$ Institute of Anesthesiologic Pathophysiology and Process Engineering, Ulm University Hospital, Ulm, Germany. ${ }^{5}$ Department of Anesthesiology, Intensive Care, Emergency and Pain Medicine, University Hospital Greifswald, Greifswald, Germany. ${ }^{6}$ Department of Anesthesiology, Emergency Medicine and General Intensive Care, State Hospital Wiener Neustadt, Wiener Neustadt, Austria. ${ }^{7}$ Division of Emergency Medicine and Intensive Care, Department Internal Medicine, Medical University Innsbruck, Innsbruck, Austria. ${ }^{8}$ Department of Internal Medicine II, Division of Cardiology, Intensive Care Unit, Medical University General Hospital, Vienna, Austria. ${ }^{9}$ Department of Anesthesiology, Perioperative Medicine and Intensive Care, Masaryk Hospital, Usti Nad Labem, Czech Republic. ${ }^{10}$ Department of Anesthesiology, Resuscitation and 
Intensive Medicine, University Hospital Hradec Králové, Hradec Králové, Czech Republic. ${ }^{11}$ Department of Anesthesiology, University Hospital Munich, Munich, Germany. ${ }^{12}$ Department of Anesthesiology and Resuscitation 5 , Azienda Ospedaliero Universitaria Pisana, Pisa, Italy. ${ }^{13}$ Department of Anesthesiology and Resuscitation 6, Azienda Ospedaliero Universitaria Pisana, Pisa, Italy. ${ }^{14}$ Division of Transplant Anesthesia and Critical Care, University School of Medicine Pisa, Pisa, Italy. ${ }^{15}$ Department of Anesthesia and Intensive Care, University Hospital of Modena, Modena, Italy. ${ }^{16}$ Aixial s.r.o, Brno, Czech Republic. ${ }^{17}$ Amomed Pharma GmbH, Vienna, Austria.

Received: 5 June 2018 Accepted: 26 October 2018 Published online: 19 November 2018

\section{References}

1. Parrillo JE. Pathogenetic mechanisms of septic shock. N Engl J Med. 1993; 328:1471-7

2. Marx G, Vangerow B, Burczyk C, Gratz KF, Maassen N, Cobas Meyer M, et al. Evaluation of noninvasive determinants for capillary leakage syndrome in septic shock patients. Intensive Care Med. 2000;26:1252-8.

3. Bhagat K, Hingorani AD, Palacios M, Charles IG, Vallance P. Cytokine-induced venodilatation in humans in vivo: eNOS masquerading as iNOS. Cardiovasc Res. 1999:41:754-64.

4. Dellinger RP, Levy MM, Rhodes A, Annane D, Gerlach H, Opal SM, et al. Surviving sepsis campaign: International guidelines for management of severe sepsis and septic shock: 2012. Crit Care Med. 2013;41:580-637.

5. Werdan K, Schmidt H, Ebelt H, Zorn-Pauly K, Koidl B, Hoke RS, et al. Impaired regulation of cardiac function in sepsis, SIRS, and MODS. Can J Physiol Pharmacol. 2009:87:266-74.

6. Schmidt H, Müller-Werdan U, Hoffmann T, Francis DP, Piepoli MF, Rauchhaus $M$, et al. Autonomic dysfunction predicts mortality in patients with multiple organ dysfunction syndrome of different age groups. Crit Care Med. 2005;33:1994-2002.

7. Schmittinger CA, Torgersen C, Luckner G, Schröder DCH, Lorenz I, Dünser MW. Adverse cardiac events during catecholamine vasopressor therapy: A prospective observational study. Intensive Care Med. 2012;38:950-8.

8. Sander O, Welters ID, Foëx P, Sear JW. Impact of prolonged elevated heart rate on incidence of major cardiac events in critically ill patients with a high risk of cardiac complications. Crit Care Med. 2005;33:81-8.

9. Rudiger $A$, Singer $M$. The heart in sepsis: from basic mechanisms to clinical management. Curr Vasc Pharmacol. 2013;11:187-95.

10. Morelli A, Ertmer C, Westphal M, Rehberg S, Kampmeier T, Ligges S, et al. Effect of heart rate control with esmolol on hemodynamic and clinical outcomes in patients with septic shock. JAMA. 2013;310:1683.

11. Leibovici L, Gafter-Gvili A, Paul M, Almanasreh N, Tacconelli E, Andreassen S, et al. Relative tachycardia in patients with sepsis: An independent risk factor for mortality. QJM. 2007;100:629-34.

12. Dünser MW, Hasibeder WR. Sympathetic overstimulation during critical illness: Adverse effects of adrenergic stress. J Intensive Care Med. 2009;24:293-316.

13. Hayase N, Yamamoto M, Asada T, Isshiki R, Yahagi N, Doi K. Association of heart rate with $\mathrm{N}$-terminal pro-B-type natriuretic peptide in septic patients: a prospective observational cohort study. Shock. 2016;46:642-8.

14. Vellinga NAR, Boerma EC, Koopmans M, Donati A, Dubin A, Shapiro NI, et al, International study on microcirculatory shock occurrence in acutely III patients. Crit Care Med. 2015:43:48-56.

15. Hoke RS, Müller-Werdan U, Lautenschläger C, Werdan K, Ebelt H. Heart rate as an independent risk factor in patients with multiple organ dysfunction: A prospective, observational study. Clin Res Cardiol. 2012;101:139-47.

16. Grander W, Müllauer K, Koller B, Tilg H, Dünser M. Heart rate before ICU discharge: A simple and readily available predictor of short- and long-term mortality from critical illness. Clin Res Cardiol. 2013;102:599-606.

17. Du W, Liu D, Long Y, Wang $X$. The $\beta$-blocker esmolol restores the vascular waterfall phenomenon after acute endotoxemia. Crit Care Med. 2017:45:e1247-53.

18. Wei C, Louis H, Schmitt M, Albuisson E, Orlowski S, Levy B, et al. Effects of low doses of esmolol on cardiac and vascular function in experimental septic shock. Crit Care. 2016;20:407.

19. Kimmoun A, Louis H, Al Kattani N, Delemazure J, Dessales N, Wei C, et al. $\beta 1$-adrenergic inhibition improves cardiac and vascular function in experimental septic shock. Crit Care Med. 2015;43:e332-40.

20. Calzavacca P, Lankadeva YR, Bailey SR, Bailey M, Bellomo R, May CN. Effects of selective $\beta 1$-adrenoceptor blockade on cardiovascular and renal function and circulating cytokines in ovine hyperdynamic sepsis. Crit Care. 2014;18(6):610.
21. Aboab J, Sebille V, Jourdain M, Mangalaboyi J, Gharbi M, Mansart A, et al. Effects of esmolol on systemic and pulmonary hemodynamics and on oxygenation in pigs with hypodynamic endotoxin shock. Intensive Care Med. 2011;37:1344-51.

22. Hagiwara S, Iwasaka H, Maeda H, Noguchi T. Landiolol, an ultrashort-acting ß1-adrenoceptor antagonist, has protective effects in an Ips-induced systemic inflammation model. Shock. 2009;31:515-20.

23. Suzuki T, Morisaki H, Serita R, Yamamoto M, Kotake $Y$, Ishizaka A, et al. Infusion of the beta-adrenergic blocker esmolol attenuates myocardial dysfunction in septic rats. Crit Care Med. 2005;33:2294-301.

24. Ackland GL, Yao ST, Rudiger A, Dyson A, Stidwill R, Poputnikov D, et al. Cardioprotection, attenuated systemic inflammation, and survival benefit of $\beta 1$ adrenoceptor blockade in severe sepsis in rats. Crit Care Med. 2010;38:388-94.

25. Wang S, Li M, Duan J, Yi L, Huang X, Chen D, et al. Effect of esmolol on hemodynamics and clinical outcomes in patients with septic shock. Zhonghua Wei Zhong Bing Ji Jiu Yi Xue. 2017;29:390-5.

26. Balik M, Ruliseky J, Leden P, Zakharchenko M, Otahal M, Bartakova H, et al. Concomitant use of beta-1 adrenoreceptor blocker and norepinephrine in patients with septic shock. Wien Klin Wochenschr. 2012;124:552-6.

27. Du W, Wang X-T, Long Y, Liu D-W. Efficacy and safety of esmolol in treatment of patients with septic shock. Chin Med J. 2016;129:1658.

28. Shang X, Wang K, Xu J, Gong S, Ye Y, Chen K, et al. The effect of esmolol on tissue perfusion and clinical prognosis of patients with severe sepsis: a prospective cohort study. Biomed Res Int. 2016;2016:1-7.

29. Wang Z, Wu Q, Nie X, Guo J, Yang C. Combination therapy with milrinone and esmolol for heart protection in patients with severe sepsis: a prospective, randomized trial. Clin Drug Investig. 2015;35:707-16.

30. Xinqiang L, Weiping H, Miaoyun W, Wenxin Z, Wenqiang J, Shenglong C, et al. Esmolol improves clinical outcome and tissue oxygen metabolism in patients with septic shock through controlling heart rate. Zhonghua Wei Zhong Bing Ji Jiu Yi Xue. 2015;27:759-63.

31. Tao $Y$, Jingyi $W$, Xiaogan J, Weihua $L$, Xiaoju J. Effect of esmolol on fluid responsiveness and hemodynamic parameters in patients with septic shock. Zhonghua Wei Zhong Bing Ji Jiu Yi Xue. 2015;27:885-9.

32. Yang S, Liu Z, Yang W, Zhang G, Hou B, Liu J, et al. Effects of the betablockers on cardiac protection and hemodynamics in patients with septic shock: a prospective study. Zhonghua Wei Zhong Bing Ji Jiu Yi Xue. 2014; 26:714-7.

33. Chen JX, Sun J, Liu YY, Jia BH. Effects of adrenergic beta-1 antagonists on hemodynamics of severe septic patients. Zhonghua Yi Xue Za Zhi. 2013;93: 1243-6.

34. Morelli A, Donati A, Ertmer C, Rehberg S, Kampmeier T, Orecchioni A, et al. Microvascular effects of heart rate control with esmolol in patients with septic shock: A pilot study. Crit Care Med. 2013;41:2162-8.

35. Plosker GL. Landiolol: A review of its use in intraoperative and postoperative tachyarrhythmias. Drugs. 2013;73:959-77.

36. Shibata S, Okamoto Y, Endo S, Ono K. Direct effects of esmolol and landiolo on cardiac function, coronary vasoactivity, and ventricular electrophysiology in guinea-pig hearts. J Pharmacol Sci. 2012;118:255-65.

37. Sasao J, Tarver SD, Kindscher JD, Taneyama C, Benson KT, Goto H. In rabbits, landiolol, a new ultra-short-acting $\beta$-blocker, exerts a more potent negative chronotropic effect and less effect on blood pressure than esmolol. Can J Anesth. 2001;48:985-9.

38. Krumpl G, Ulč I, Trebs M, Kadlecová P, Hodisch J, Maurer G, et al. Pharmacodynamic and -kinetic behavior of low-, intermediate-, and highdose landiolol during long-term infusion in whites. J Cardiovasc Pharmacol. 2017;70:42-51.

39. Singer M, CS D, Seymour $C$, et al. The third international consensus definitions for sepsis and septic shock (sepsis-3). JAMA. 2016;315:801-10.

40. Rhodes A, Evans LE, Alhazzani W, Levy MM, Antonelli M, Ferrer R, et al. Surviving Sepsis Campaign. Crit Care Med. 2017:45:486-552.

41. Sanfilippo F, Santonocito C, Morelli A, Foex P. Beta-blocker use in severe sepsis and septic shock: a systematic review. Curr Med Res Opin. 2015;31: 1817-25.

42. Ogura $Y$, Jesmin S, Yamaguchi N, Oki M, Shimojo N, Islam MM, et al. Potential amelioration of upregulated renal HIF-1alpha-endothelin-1 system by landiolol hydrochloride in a rat model of endotoxemia. Life Sci. 2014;118:347-56.

43. Mori K, Morisaki H, Yajima S, Suzuki T, Ishikawa A, Nakamura N, et al. Beta-1 blocker improves survival of septic rats through preservation of gut barrier function. Intensive Care Med. 2011;37:1849-56. 
44. Seki Y, Jesmin S, Shimojo N, Islam MM a, Rahman MA r, Khatun T, et al. Significant reversal of cardiac upregulated endothelin-1 system in a rat model of sepsis by landiolol hydrochloride. Life Sci. 2014;118:357-63.

45. Schmittinger CA, Dünser MW, Haller M, Ulmer H, Luckner G, Torgersen C, et al. Combined milrinone and enteral metoprolol therapy in patients with septic myocardial depression. Crit Care. 2008;12(4):R99.

46. Matsuishi Y, Jesmin S, Kawano S, Hideaki S, Shimojo N, Mowa CN, et al. Landiolol hydrochloride ameliorates acute lung injury in a rat model of early sepsis through the suppression of elevated levels of pulmonary endothelin-1. Life Sci. 2016;166:27-33.

47. Azimi G, Vincent JL. Ultimate survival from septic shock. Resuscitation. 1986; 14:245-53.

48. Parker MM, Shelhamer JH, Natanson C, Alling DW, Parrillo JE. Serial cardiovascular variables in survivors and nonsurvivors of human septic shock: Heart rate as an early predictor of prognosis. Crit Care Med. 1987:15:923-9.

49. Okajima M, Takamura M, Taniguchi T. Landiolol, an ultra-short-acting $\beta 1$ blocker, is useful for managing supraventricular tachyarrhythmias in sepsis. World J Crit Care Med. 2015;4:251-7.

50. Tamura T, Yatabe T, Yokoyama M. Prevention of atrial fibrillation after cardiac surgery using low-dose landiolol: A systematic review and metaanalysis. J Clin Anesth. 2017;42:1-6.

51. Nagai R, Kinugawa K, Inoue H, Atarashi H, Seino Y, Yamashita T, et al. Urgent management of rapid heart rate in patients with atrial fibrillation/flutter and left ventricular dysfunction: comparison of the ultra-short-acting $\beta 1$-selective blocker landiolol with digoxin (J-Land Study). Circ J. 2013;77:908-16.

52. Syed YY. Landiolol: a review in tachyarrhythmias. Drugs. 2018;78:377-88.

53. Krumpl G, Ulc I, Trebs M, Kadlecová P, Hodisch J. Bolus application of landiolol and esmolol: comparison of the pharmacokinetic and pharmacodynamic profiles in a healthy Caucasian group. Eur J Clin Pharmacol. 2017;73:417-28.

54. Krumpl G, Ulc I, Trebs M, Kadlecová P, Hodisch J, Maurer G, et al. Pharmacokinetics and pharmacodynamics of low-, intermediate-, and highdose landiolol and esmolol during long-term infusion in healthy whites. J Cardiovasc Pharmacol. 2018;71(3):137-46.

55. Krumpl G, Ulc I, Trebs M, Kadlecová P. Hodisch J. Pharmacokinetics and pharmacodynamics of two different landiolol formulations in a healthy Caucasian group. Eur J Pharm Sci. 2016:92:64-73.

56. Ikeshita K, Nishikawa K, Toriyama S, Yamashita T, Tani Y, Yamada T, et al. Landiolol has a less potent negative inotropic effect than esmolol in isolated rabbit hearts. J Anesth. 2008;22:361-6.

Ready to submit your research? Choose BMC and benefit from:

- fast, convenient online submission

- thorough peer review by experienced researchers in your field

- rapid publication on acceptance

- support for research data, including large and complex data types

- gold Open Access which fosters wider collaboration and increased citations

- maximum visibility for your research: over $100 \mathrm{M}$ website views per year

At $\mathrm{BMC}$, research is always in progress.

Learn more biomedcentral.com/submissions 